\title{
Egoistic Rationality and Public Choice: A Critical Review of Theory and Evidence*
}

\author{
JOHN QUIGGIN \\ Australian National University, \\ Canberra, ACT 2600
}

\begin{abstract}
Over the past 20 years there has been a rapid development of public-choice theory: that is, the application of an assumption of egoistic utility maximization to political behaviour. In this paper it is argued that, in important areas, the available empirical evidence runs counter to this theory. The continuing work in this area therefore reflects ideological, rather than explanatory or predictive, concerns.
\end{abstract}

\section{Introduction}

Until fairly recently the discipline of economics was notable for its sharp separation from other 'social sciences', such as sociology, psychology and political science. The main reason for this was economists' commitment to the use of a very simple model of human behaviour. This model, which may be termed 'egoistic rationality', was based on the idea of individuals maximizing utility as a function of their personal consumption of goods. While it generally was admitted that this was not a 'realistic' model of human behaviour, it was claimed that what mattered was the ability to yield sharp, and accurate, predictions in relation to the (aggregate) behaviour of markets.

In more recent times, this attitude has changed. However, far from re-examining economic models in the light of evidence relating to human behaviour, economists have adopted an 'imperialistic' approach.' The concepts and

- I would like to thank Tony Chisholm, Geoff Brennan, Fred Gruen and Jonathon Pincus for their helpful comments and criticism. Obviously, none of them should be assumed to share the views expressed here.

- This terminology is due to Boulding (1969) and has also been used by Tullock (1972). methods of neoclassical economics have been applied to a wide range of problems in other social science areas, such as crime, marriage and divorce. Becker (1976) is a leading example. In many cases the results have been widely viewed as disappointing, and as common sense dressed up in fancy economic clothes. ${ }^{2}$ Relatively few of these forays have laid the basis for continued exploration (or colonization).

One area where research has continued, and indeed expanded rapidly, has been 'public-choice theory' or the 'neoclassical theory of politics'. This area, unlike the others mentioned above, is of direct importance to economists, since their analysis is normally undertaken with the objective of yielding policy recommendations. Moreover, the results yielded by public-choice theory are generally attractive to neoclassical economists. Over the last 100 , and particularly the last 50 , years most democratic States have adopted increasingly interventionist policies, thereby moving in a direction opposite to that recommended by

2 An exureme example is Fair (1978), who uses the full apparatus of utility theory to deduce that women in unhappy marriages are more likely to have affairs. Blaug (1980, Chap. 14) gives a more detailed discussion of this area of research. 
neoclassical analysis. Public-choice theory, based on the assumption of egoistic rationality, offers explanations of this phenomenon which are unfavourable to political processes, and favourable to neoclassical analysis.

A second, and perhaps equally important, factor explaining the appeal of public-choice theory to economists relates to the style of explanation which it employs. Whereas traditional political science is characterized by a substantial amount of descriptive work and the use of a wide variety of explanatory factors, public-choice theory is based on a system of logical deduction from a very parsimonious set of axioms. Complex and varied phenomena are given an internally consistent explanation which may be characterized as an equilibrium arising from the independent optimizing choices of a number of agents. The latter style of explanation enjoys a far higher status in the economics profession than the former. Indeed, this status difference is greater in economics than in almost any other discipline, including most of the physical sciences. The axiomatic approach has great strengths, notably the potential to expose key assumptions, and to generate sharp, testable predictions. However, there is a danger that the preference for this style of argument will be permitted to bias the interpretation of empirical tests, so that failed predictions are ignored or explained away. If this is done, the apparent advantages of rigor largely become illusory.

In this paper it will be argued that the egoistic rationality assumption is radically at variance with the available empirical evidence. The paper will begin with a summary of standard public-choice theory as it describes voters, politicians and political processes, and an examination of some implications of the theory. This will be followed with a range of evidence which contradicts these predictions. Finally some observations on methodology, and some suggestions for alternative approaches, will be offered.

\section{An Outline of Public-Choice Theory}

Before commencing an outline of public-choice theory it will be useful to clarify some terminology. The term 'neoclassical' will be used in a fairly strict sense to refer to those economists who accept the validity, at least as a guide to most policy issues, of the competitive model in which all markets clear and 'imperfections' such as monopoly and externalities are fairly unimportant. An alternative usage would be to label all 'mainstream' economists as neoclassical and to use some term such as 'Chicago school' to refer to advocates of laissezfoire. I have not adopted this usage, partly because I think it understates the predominance of freemarket attitudes in mainstream thinking, and partly because the term 'Chicago' is also used as a codeword for certain positions on debates within publicchoice theory.

A similar clarification is needed with respect to the term 'public-choice'. A number of writers, notably Arrow (1951) and Black (1958), have examined problems associated with the pure logic of voting, without any assumptions as to whether motivation is egoistic or altruistic. This work, which will not be examined here, has only a limited connection with the main body of public-choice theory based firmly on the assumption of egoistic rationality.

Mueller $(1979$, p.1) summarizes this tendency, stating 'The basic behavioural postulate of publicchoice, as for economics, is that man is an egoistic, rational, utility maximiser'. This is frequently contrasted with the assumption, allegedly implicit in previous approaches to the problem, that politicians act as benevolent dictators. While not all economists with an interest in political behaviour would accept these definitions, there is no doubt that Mueller's definition fits the dominant tendency in public-choice theory, arising out of the work of Downs (1957). In the present discussion the term 'public-choice' will be taken to refer to the body of work based on the assumption of egoistic rationality.

With respect to voters, the first prediction yielded by public-choice analysis is that they should not vote at all. The basic argument is given by Downs (1957, pp. 265-7). Because the chance of exercising a decisive vote (i.e. the chance of a tied election) is tiny compared to any realistic estimate of the private individual benefits of the different possible outcomes, the expected benefits of voting are negative. The fact that people do vote is a major problem for public-choice theory, known as the paradox of voting or Downs' paradox.

However, given that individuals do vote, they will not make well-informed choices. Once again, the low probability of exercising a decisive vote means that the individual will be 'rationally ignorant' concerning political issues (Downs, 1957, p. 259). By contrast, individuals will invest in the acquisition of appropriate amounts of information in making market decisions, e.g. relating to the purchase of consumer goods.

Because of the rational ignorance argument 
(backed up by doubts as to whether voters really are rational) voters do not play a major role in most public-choice theories of politics, though some strands of public-choice thinking are more emphatic in this respect than others. Rather, politics is seen as a process involving interactions between politicians and interest groups or 'lobbies'.

Politicians are, of course, seen as narrowly selfinterested. This means that they have no direct interest in having any particular policies adopted (other than measures affecting their own salaries etc.). Policies are simply the stock-in-trade of political entrepreneurs. It is not completely agreed how politicians advance their interests. On the simplest view, they simply seek to obtain and retain political office, with its associated prerequisites. This is the view of Downs (1957) and Breton (1974). Alternatively, they may act as 'agenda setters', exploiting the paradoxes of voting, and manipulating issues in the hope of extracting rent. McKelvey (1976) and Levine and Plott (1977) present this argument in detail.

The role of lobby groups is somewhat more clearly defined. Lobby groups organize to seek government intervention which advances the interests of their members. The main difficulty facing these groups is the free-rider problem, which is at the bottom of Downs' paradox. In most cases individuals will find it preferable to passively benefit from the activities of lobbyists. Thus, the successful lobbies will be those which represent concentrated and easily organized interests. Since the adoption of policies depends on the strength of the lobbies for and against, the political process will favour policies with concentrated gainers and dispersed losers. Olson (1965) gives a detailed analysis of this process.

Political parties play a relatively small role in public-choice theory. There are a number of reasons for this. First, there is the limited role of parties in the political system of the United States, which is the home of public-choice theory. Second, it is clear that traditional views of political parties as 'associations of like-minded people' have no role to play in public-choice theory. Finally, even if parties are viewed as coalitions of interest groups, their existence and stability pose major problems for public-choice theory, which will be discussed below. Nevertheless, in countries like Australia, political parties cannot be ignored completely. Most public-choice theorists argue that lobby groups located in marginal seats will do particularly well; and marginal seats cannot be defined in the absence of political parties.
The above may seem like a caricature of publicchoice theory. However, the real problem is that 'public choice models seem but a naive caricature of political behaviour' (Mueller, 1979, p.7) except to those already committed to the postulate of egoistic rationality. Like other caricatures, these models present certain recognizable features, exaggerated out of all proportion. The results of public-choice theory thus have some immediate appeal, especially to neoclassical economists, but do not stand up to empirical scrutiny.

\section{Implications}

Public-choice theory has widespread ramifications, both for the way in which economists work, and for the basic organization of political systems. Economists have typically analyzed government policies (other than explicitly redistributive policies) on the basis of efficiency criteria. If existing policies are deemed to promote efficiency (relative to non-intervention and to available alternative policies) they are deemed to be justified. Otherwise alternatives are advocated. For example, intervention to deal with environmental 'externalities' is generally considered to be justified. However, economists in the 'efficiency' framework have generally argued for price-based measures (e.g. Pigovian taxes) rather than regulations.

Economists influenced by public-choice theory have tended to treat this approach with scorn. Caves (1976, p. 279) describes it as 'cranking out blueprints for the Wise Statesman'. Rather they seek to explain government policies on the basis of interest group analysis. For example, environmental regulation may be explained as an entry-limiting device, creating an effective cartel (Buchanan and Tullock, 1975). The interest group approach is used even when the policies concerned appear to be preferable on efficency grounds. For example, Maloney and McCormick (1982) extend the Buchanan-Tullock argument to the problem of why pollution permits or rights are often nontradeable. Following the cartel analysis, they argue that if monitoring costs are high, such a rule may permit savings which offset the benefits of trade among cartel members. They do not observe that it is precisely in the case of high monitoring costs that regulatory measures such as non-transferable permits will be preferable, on efficiency grounds, to market-oriented measures such as Pigovian taxes.

The public-choice approach does have the merit 
of focusing attention on the distributional effects of policy changes, which are frequently ignored by economists working in the 'efficiency' tradition. Frequently, however, as in the case above, it tends to the opposite extreme. The implicit assumption that all government activity consists solely of redistribution leads rapidly to the conclusion that intervention is a 'negative-sum game' (Mueller, 1979). This adverse attitude to government has led some public-choice theorists to propose strict constitutional limits on the powers of democratic governments, notably the power to tax (Brennan and Buchanan, 1982).'

\section{The Evidence-Voters}

As was noted above, the fact that people vote voluntarily is a major problem for public-choice theory. Initially, voting was 'explained' by postulating a 'taste for voting', but the circularity of this argument rapidly became apparent (e.g. Breton, 1974). Two main approaches to the problem of reconciling voting with egoistic utility maximizing have been tried. The first is an attempt to meet Downs' paradox head-on by arguing that the probability of a decisive vote is relatively high. For example, it is argued that if each individual voter is equally likely to vote either way then the binomial theorem yields a probability of a tie of the order of $n^{-1 / 2}$ where $n$ is the number of voters (Beck, 1975). Unfortunately this approach also implies that the result of, say, a US presidential election can be known, with virtual certainty, to within a few thousand votes. Any more realistic model yields a probability of the order of, though perhaps greater than, $1 / n$ (Chamberlain and Rothschild, 1981). Assuming that individuals are only concerned with the effects on themselves, and not on others, this means voter turnout should decline rapidly as the electorate increases in size.

The alternative approach has been to suggest that people do not vote 'instrumentally', that is in order to influence the result, at all. Rather, they vote for purely expressive reasons in order to state a preference for one candidate or a dislike for another (Brennan and Buchanan, 1984). This approach has the merit that, at least on some interpretations, it opens the door to altruistic and

${ }^{3}$ Surprisingly enough, most public-choice theorists seem to take some form of democracy as a given. On a public-choice view, a system of limited hereditary monarchy would seem to offer obviously advantages, such as a clear definition or political 'property rights'. other non-egoistic motivations, yet it encounters problems almost as severe as those for the taste for voting' explanation. For, if the hypothesized desire to express political opinions (in the absence of any influence of outcomes) actually existed, we would expect to find independent confirmation of its existence. This could take the form of market provision of opportunities for such expression, e.g. through political meetings, straw polls, buttons and bumper stickers. In reality the proportion of the population who take advantage of such opportunities is very small. We are left, then, with a desire to express opinions which, for some reason, can only be satisfied by voting, i.e. a taste for voting.

The expressive voting hypothesis also yields poor predictions of voting behaviour. The most obvious problem is 'tactical voting'. In first-past-the-post systems most voters confine their attention to candidates with some chance of winning, ignoring third-party and independent candidates even if they are more attractive. This is difficult to explain unless voters actually wish to influence the result. Tactical voting is less common under the preferential system used in Australia. However, it has occurred, notably in normally safe seats where an attractive centre candidate emerges. In this case the centre candidate can be elected only if the minority party candidate finishes third and has their preferences distributed. To improve the chances of this, supporters of the minority party may divert their votes to the centre party candidate."

Another difficulty for the expressive voting hypothesis is the fact that, in voluntary systems, turnout is generally lower in safe seats than in marginal ones. See, for example, Riker and Ordeshook (1968) and Ashenfelter and Kelley (1975). It can be argued that people are most interested in expressing their opinion when the nation is closely divided, but it seems difficult to extend this argument to individual seats.

A third problem is why voting behaviour differs systematically between general elections and byelections, in that the anti-government swing is, on average, larger in by-elections. From an instrumentalist' perspective this difference is easily explained by the fact that a vote in a general election can contribute to a change of government, whereas one in a by-election cannot. Thus, voters

- This occurred in the 1981 NSW election, in the normally safe Liberal seat of North Sydney. An independent, Mr Ted Mack, was elected on ALP preferences. 
in by-elections can place greater emphasis on local issues, the personal merits of the candidates, the desire to protest against specific policies etc. By contrast, on the expressive view, there is no obvious reason why people should express themselves differently at by-elections.

Thus, it would appear that there is strong evidence that voting behaviour is both ends-directed and rational. That is, electors choose to vote because of the effects their vote will have, and do not vote if these effects are insufficient to outweigh the costs of voting. However, as Downs' paradox shows, rationality and egoism together imply nonvoting. The evidence suggests that egoism is the postulate which must be abandoned.

The defects of public-choice explanations of voter turnout have been widely recognized. This has not, however, affected the enthusiasm with which the closely related idea of 'rational ignorance' has been received. This idea is open to logical and empirical objections almost as severe as those relating to the analysis of voting.

First, even if the rational ignorance hypothesis were empirically valid, it would not justify the assumption, frequently derived from this hypothesis, that politicians can effectively ignore the true interests of voters. This is because voters require very little information (at least in a two party system) to apply manipulation-proof voting strategies. For example, suppose voters choose whether to vote for or against the government solely on the basis of whether they personally are better or worse off than at the last election. This strategy may lead some voters to cast votes which are not in their own best interests but, on average, it will lead to the elimination of governments which adopt policies that are against the interests of a majority of voters. Of course, manipulation-proof strategies employing more information would yield votes which were more frequently in line with voters' 'true' interests. It remains a difficult question to determine theoretically the socially optimal level of information collection by voters, let alone obtain empirical estimates.

It is, however, clear that many, though not all, voters collect much more political information than would be predicted on the basis of 'rational ignorance'. For example, there is substantial market provision of political information through newspapers, magazines etc. By contrast, the bulk of market 'information' about consumer goods is provided through advertising, much of which is consumed involuntarily. Most of the empirical support for the idea of rational ignorance comes from studies of voter 'apathy', which reached particularly strong conclusions in the 1950s. However, 'apathy' appeared to decline sharply in the 1960 s as concern about issues such as Vietnam mounted, and political polarization increased. For the contrasting views, see Campbell et al. (1960) and Nie et al. (1976). As in the case of voting, this suggests that voters' interest in political information increases with the importance of political choices. Once again, this is consistent with rationality but not with egoism.

The way in which 'rational ignorance' has been used to dismiss voters as independent actors raises some interesting parallels. The most obvious is the treatment of consumers in some institutionalist analyses of the corporate sector, of the type popularized by Vance Packard. Here, the assumption that consumers can be freely manipulated by the 'hidden persuaders' of the advertising world plays a role very similar to that of 'rational ignorance' in the public-choice literature. The parallel is even closer in some cases. Riker and Ordeshook (1968) seek to explain voting behaviour by suggesting that pro-voting 'propaganda' leads people to over-estimate the importance of their vote.

Given the empirical inaccuracy of the picture of voters presented by orthodox public-choice theory, its ready acceptance by economists calls for some explanation. In my view the public-choice theory draws much of its emotional support from a far older view of the democratic electorate - that of the irrational, easily manipulated mob. Of course, given economists' professional commitment to rationality assumptions, this view rarely makes it to centre stage, but it is certainly perceptible in some of the literature. Terms such as 'myopia' (Nordhaus, 1975), xenophobia' (Anderson, 1980) and 'rabble' (Buchanan, 1977, p. 122) are used fairly freely. As Mueller (1979, p.105) says, 'the assumption that the electorate is "ignorant and greedy" underlies much of the public choice literature'. The quote is from Bagehot's (1905) attack on proposals to enfranchise the working classes.

\section{$V$ The Evidence-Politicians and Ideology}

In the general discussion of political processes, politicians usually are seen as being influenced largely by ideology, on the one hand, and public opinion, on the other. Ideology is taken here, not in the sense of an organized and coherent system of ideas, but broadly, to cover any beliefs, 
systematic or otherwise, on the social desirability of particular policies. Public-choice theory, through the 'rational ignorance' argument, largely removes public opinion from the scales. This is balanced by the exclusion of ideology. What remains is an amoral process of trade among organized interest groups, mediated by politicians.

The most obvious evidence against this analysis is the fact that many politicians are closely identified with particular viewpoints, and act to advance those viewpoints even at the expense of their own apparent interests. This occurs even among politicians with ideologies based on an axiom of self-interest. Studies illustrating this, with reference to US legislators, include Kau and Rubin (1979) and Kau (1981). They show that broad measures of ideology (e.g. ratings by liberal or conservative groups) predict voting choices better than measures of constituency interests. Kalt and Zupan (1984) give a detailed theoretical and empirical analysis of this problem.

This type of behaviour can be explained without invoking assumptions of altruism on the part of politicians. It may, for example, be argued that a process similar to that of establishing a brand-name identity for a product is at work. There are, however, a number of difficulties here. First, it would seem plausible that this can be done most effectively by a candidate who actually believes in the 'product' he is selling. Given the substantial excess supply of would-be politicians, and the fairly rapid turnover among them, it seems reasonable to suppose that most of the time, policies will be implemented by people who actually believe in them.

A more fundamental problem is for whose benefit the brand name is being established. The well-organized interest groups which dominate the public-choice view of the political process have no obvious need for such consistency. The obvious interpretation is that the brand name is established for the electorate at large. This, of course, in violation of the 'rational ignorance' theory. Moreover, it leads fairly rapidly to the conclusion that politicians have relatively little scope for the kinds of manoeuvres which public-choice theory requires of them. They must, to a large extent, stand or fall with particular policy packages, and the choice between these packages is exercised by the electorate rather than by interest groups.

Thus far, like most public-choice theorists, I have focused my attention on individual politicians, at the expense of the most pervasive feature of modern politics, the party system. As has been observed by Tullock (1982), the very existence of a stable party system is a major embarrassment for public-choice theory. For, given the assumption that political processes represent alliances of convenience between organized interest groups, we should expect to see frequent shifts of allegiance and the formation of successive majority coalitions. In fact, even in relatively fluid political systems, such as those of the US and Italy, long-lived coalitions are common and sharp changes of allegiance rare. Tullock offers a number of possible explanations. However the important thing is that, as in the case of Downs' paradox, the logic of public-choice theory produces an initial prediction (the extreme instability of political parties and coalitions) which is inaccurate. As long as this is recognized, it is usually possible to 'save the phenomena' by means of auxiliary hypotheses. However, in most areas of politics the facts are not so obvious. Thus, it is possible for quite inaccurate propositions to go unrefuted because they have the seeming surety of deductive logic.

One feature of the party system which must be mentioned is the role of marginal seats. It may usually be observed that, especially around election time, the inhabitants of marginal seats receive, or are promised, various favours from governments. Advocates of public-choice theory have incorporated this fact into their analysis. However, it has not been noticed that the character of marginal seats is the opposite of that which would be predicted by public-choice theory. This approach would suggest that the best-organized lobbies should get the most prizes. In terms of electorates this would mean that marginal seats should be of homogeneous social composition and possess strong local organizations. Thus, we should see organizations like the AMFSU and LGPA, and seats like Shortland and Darling Downs, swinging regularly between the parties. In fact the opposite is true. The swinging seats are those which are most mixed in social composition and least open to organization. This reflects the fact that political parties, in most Western countries, are based on broad social classes, rather than more-or-less random agglomerations of interest groups.

A final feature of public-choice theory, or rather rhetoric, which must be mentioned is the assertion that alternative theories of the State, popular among economists, rest on the assumption that politicians are pure altruists. This is simply untrue. While I believe that politicians, like other people, display both altruistic and selfish behaviour, it is perfectly possible to obtain socially optimal policies 
from purely selfish politicians. All that is required is 2 well-informed electorate and a smsothly working electoral system.

\section{The Evidence - Interest Groups}

Interest, or "lobby', groups play a central role in public-choice theory, and bave been the main focus of empirical work based on this approach. This empirical work is remarkable, both for the regularity with which key predictions of publicchoice theory have been violated, and for the enthusiasm with which success has been claimed for the public-choice approach.

One particularly important area of application has been the tariff and other forms of protection. This area is of some importance for the development of public-choice theory. Well before public-choice theory existed in a formal sense it was part of economic folklore that tariffs persisted because the gains went to a small and concentrated group while the costs were thinly spread across the community. In many ways this simple idea was the forerunner of the full-blown interest group analysis of public-choice theory.

The historical accuracy of this explanation is doubtful. In most countries the tariff was not introduced on an industry-by-industry basis. Rather, it came in 'actoss-the-board' as a result of contests between protectionist and free-trade political parties.' Thus, both gainers and losers were large and dispersed groups.

The importance of concentrated interests in public-choice theory is nevertheless undoubted. Virtually all theoretical discussions follow Olson (1965) in according concentration pride of place among the factors which determine the strength of lobby groups. Moreover, it is one variable which is common to nearly all empirical analyses of the tariff.

The empirical results are striking. In studies of Australia (Anderson, 1980), Canada (Caves, 1976) and the United States (MacPherson, 1972; Finger et al., 1982) industry concentration has been found to be negatively, and significantly, related to success in obtaining assistance. Numerous explanations, of varying credibility, have been offered for this phenomenon. However, none of these authors has suggested that any fundamental revisions to public-

- Tariffs have been the main basis of political division in most English-speaking countries at one time or another. Examples include Australia in the early years of Federation, and the US in the late 19th century. choice theory are warranted. Moreover, the assumption of a positive relationship between concentration and assistance remains a standard feature of most presentations of public-choice theory. The hypothesis appears virtually invulnerable to empirical refutation.

Partial exceptions to this pattern are the study of the 1824 US tariff by Pincus (1975) and the recent work of Dougan (1984). Pincus finds a fairly weak positive association between industry concentration and protection, but this is of fset somewhat by a strong positive association between protection and the number of firms in an industry. Unlike the other writers cited above, Pincus takes some account of the impact of the general debate between free-traders and protectionists, and notes that it was a disadvantage for an important duty to be identified as too local or narrow an interest'. Dougan (1984) criticizes the econometric approach of previous studies, rejects the hypothesis that industry concentration is a major determinant of protection, and provides some public-choicetheoretic grounds for this. Like a number of the studies mentioned above, Dougan finds that labour-intensity is an important factor in determining protection rates. This implies that a simple class-based analysis, drawing on the StolperSamuelson theorem, could well outperform the interest group approach. This point is discussed further by Quiggin and Stoeckel (1982). As with voters and politicians, the key predictions of orthodox public-choice theory with respect to interest groups are unreliable in the case of tariffs. A substantially more sophisticated theory is clearly required. However, because very few of the studies cited above have drawn attention to the failure of these key predictions, the impression is widespread that this is an area where public-choice theory has been highly successful.

A second area where public-choice theorists have claimed a great deal of success, on dubious empirical grounds, has been the analysis of environmental policy. A simple application of public-choice reasoning would seem to suggest that the policy process should severely under-supply environmental goods, since the beneficiaries are usually numerous and often widely dispersed. However, public-choice theorists have shown (retrospectively) that a more detailed analysis gives a correct prediction of extensive environmental regulation.

As noted above, public-choice theorists such as Maloney and McCormick (1982) have claimed that the introductions of environmental controls may 
be regarded as devices created in the interests of the regulated firms in order to support a cartel. There are a number of difficulties with this claim. The first is the obvious fact that businesses have generally opposed environmental controls (though public-choice theorists make much of the exceptions). The second is that, since such controls affect only domestic production, the cartel explanation works only for non-traded goods, or goods where imports are subject to quota restrictions. The third is that, unless the added support of environmentalists is crucial (and publicchoice theory predicts that they should be very weak) it would make much more sense to lobby for direct legislative sanction for a cartel, without the additional costs associated with environmental controls.

Thus far I have examined predictions which are, at least in principle, refutable. Some public-choice theorists have adopted immunizing strategems which avoid any possibility of refutation. The most important of these is derived from the simple observation that any policy change yields gainers and losers. Hence, any change can be 'explained' by identifying the gainers.

As long as the interest group theory is explicitly treated as a maintained hypothesis, as in Sieper (1982), there is nothing necessarily wrong with this. However, there is a persistent tendency to claim successful 'explanations' of this kind as evidence supporting the interest group approach. For example, Maloney and McCormick (1982) argue that the frequency of 'grandfather clauses' exempting existing equipment from pollution controls support the interest group theory, which suggests that such controls are typically entrylimiting devices. On the other hand, uniform controls without such exemptions also support the theory since they redistribute income within the industry towards those who can meet the controls most cheaply.

What is needed, but has rarely been offered, is a sharp a priori prediction of the groups likely to have disproportionate influence in a given situation, combined with rigorous empirical testing of the hypothesis that policies favouring these groups will be adopted.

\section{Methodological Implications}

The majority of neoclassical economists are at least nominal adherents of the 'positivist' methodology advanced by Friedman (1953). On this view, the assumptions underlying economic analysis are merely instruments, and their truth or otherwise is a matter of no concern. What matters is that, in any given area of interest, these assumptions can be used to generate 'good' predictions. Even where alternative methodological frameworks, such as those of Popper and Lakatos, are entertained, the validation or reputation of predictions is of vital concern.

On the simple instrumentalist view expressed by Friedman, it seems clear that public-choice theory should have abandoned the assumption of egoistic rationality long ago. The erroneous predictions described above relate to key issues. When those incorrect predictions are dropped, the theory yields a picture of the political system very similar to that of 'pluralist' political scientists (at least the more pessimistic ones). Thus, the use of the egoism assumption yields much that is novel, and much that is at least arguably true, but little that is both novel and true. It would seem that the 'positivist' methodology functions less as a guide to economists, than as a convenient justification of some existing practices.

Some public-choice theorists have responded to the predictive failures of the theory by moving away from the concept of prediction as a key test of theory. For example, Judge (1978, p. 14) supports the viewpoint (which he attributes to Buchanan) that it is less important to develop testable propositions in the public-choice mould than to develop sophisticated but plausible theories'. Rowley (1978, pp. 38-9) goes further, admitting the empirical weakness of public-choice theory, but arguing that it is validated by the 'market test' of widespread acceptance. On this basis, astrology might be adjudged superior to astronomy!

A more sophisticated approach to the problem is adopted by Brennan and Buchanan (1983). They argue that because of aggregation bias estimates of the welfare costs of political institutions based on the performances of 'average' institutions will be biased downwards. Thus, even if analysis based on the egoism assumption yields worse predictions than analysis which incorporates altruism, it should be preferred because its excessive pessimism will tend to cancel out the effects of aggregation bias. Thus, 'for purposes of constitutional dialogue, the model which embodies self-serving behaviour on the part of all politicians may be superior to that which accurately predicts behaviour in the conventional probabilistic sense' (p. 103).

Not all public-choice theorists have abandoned prediction as the acid test of theory. In cases where theory fails the tests which its practitioners initially 
impose, it is usually possible to find a more 'sophisticated' test which yields better results (an example is Peltzman, 1984). Alternatively, it may be argued (Rowley 1978, Muellex 1979) that the theory is simply too new to permit definitive testing. Like the 'infant industry' argument, this claim cannot be refuted. However, more than 25 years after the publication of Downs' book, it would seem to be wearing a bit thin.

The methodological approach of Lakatos, based on the concept of 'scientific research programs', may be used to analyze some of these developments. Lakatos argues that scientific research programs are characterized by central 'core hypotheses', and a 'protective belt' of auxiliary hypotheses. The hard core is treated as irrefutable by the protagonists of the program. Any testable prediction is derived from a combination of 'central' and 'auxiliary' hypotheses. If the prediction is empirically falsified, the auxiliary hypotheses, and not the hard core, are adjusted. A more detailed description of the Lakatos approach, with economic applications, is given by Blaug (1980).

One feature of Lakatos' approach which is particularly important in the present context is the notion that the hard core consists not only of factual propositions but also of a commitment to a particular 'heuristic' or style of explanation. For many economists, the assumption of egoistic rationality is attractive less because they actually believe decisions are primarily motivated by selfinterest than because this assumption is particularly conducive to a 'rigorous' style of argument in which phenomena are explained in terms of an equilibrium arising from the independent solution of individual maximization problems.

In Lakatosian terms, the changes in auxiliary hypothesis which may be observed within publicchoice theory are indicative of a degenerating research program. That is, the adjustments act not to yield predictions of 'novel, hitherto unexpected facts', but to 'save the phenomena', i.e. to accommodate the program to facts which contradict its original predictions. Alternatively, they act as, immunizing stratagems' which logically preclude the possibility of refutation.

A more charitable approach may be taken if public-choice theory is viewed in the context of the

- Peltzman seeks to refute the findings of studies such as Kau and Rubin (1979), referred to above, claiming that 'ideology' is explained by variables such as the degree of union funding a legislator receives. There is an obvious problem of causality here, which is not addressed. total neoclassical program. This involves not only a scientific research program, but also what Blaug (1980) terms a political action program, consisting principally of the laissez-faire package of policies. In this broader context, public-choice theory itself plays the role of an auxiliary hypothesis, used to explain the rejection of the neoclassical political action program, and to support changes to political systems which would facilitate its adoption. Given the emphasis of neoclassical economics on individual egoism, it clearly is necessary that auxiliary hypotheses should not contradict this assumption. Thus, the evaluation of public-choice theory must depend, in part, on the value placed on neoclassical economics as a whole. Conversely, of course, the weaknesses of public-choice theory have implications for the broader neoclassical program.

In summary, the continued adherence of economists to the research program of publicchoice theory, despite its poor predictive record, may be explained by a variety of features of the program including its style of explanation and its consistency with 'hard-core' beliefs about the nature of political processes. However, these considerations do not justify a refusal to face up to the empirical failures of the program, and they demand a willingness to consider alternative approaches.

\section{Alternative Approaches}

The empirical evidence presented above suggests that public-choice theory does not offer a strong challenge, on grounds of superior predictive ability, to existing theories of political processes. However, while these theories may be superior on predictive grounds, they are not easily integrated with existing economic theories of the market. The discussion of the previous section indicates that any alternative theory of political processes must, to some extent, yield an alternative theory of market processes. As Brennan and Buchanan (1981) argue, any attempt to compare political and economic processes must be based on a model of human behaviour which is applied uniformly to both sets of processes.

As has been shown, approaches based on individual egoism work very badly in modelling political processes. Since the abandonment of methodological individualism would require the complete abandonment of the neoclassical research program, it is unlikely to be considered by economists. Hence, in this section, only modifications of the egoism assumption will be 
considered. Furthermore, the style of explanation will be kept as close as possible to that prevailing in public-choice theory. Given space limitations, the objective will be to indicate possible alternative directions, rather than to present detailed analysis.

The simplest change would be to replace the assumption of pure selfishness with one of 'selfcentredness'. That is, individuals would be presumed to decide their actions on the basis of a calculus which put a high weight on their own welfare, and that of their immediate family, a somewhat lower weight on that of friends and relatives, and a still lower weight on others. (The weight could be modelled as a declining function of 'distance' from the individual - hence the term 'self-centred'.)

This model would meet the Brennan-Buchanan requirement that it should yield $a$ uniform account of both market behaviour and political behaviour. Indeed, assuming that the usual neoclassical assumptions of convexity, atomism and complete markets are satisfied, its predictions of market choices would be identical to those of the standard neoclassical model. The most interesting point arises in the case when the individual's welfare function would be increased by transfers to another person. (In order for this to occur, it would be necessary for the beneficiary to have a higher marginal utility of money than the donor and also a fairly high proximity weight, e.g. a poor cousin). In this case, the basic theorems of welfare economics may be applied to show that the donor should not alter his market behaviour (e.g. by supplying goods at reduced prices), but should rely on cash transfers.

If the neoclassical assumptions are violated,the egoistic and self-centred models will yield different predictions. For example, whereas the egoistic model will predict that the viability of cartels and trade unions will depend solely on the benefits to individuals at staying in or defecting, the selfcentred model suggests that the collective benefits will be taken into account with a weight depending on the 'closeness' of the members. Without a much more extensive analysis, it is difficult to say which model is better in this area.

The major differences would arise in relation to predictions of political behaviour, and here the selfcentred model is superior in a number of ways. First, the model yields a fairly good explanation of observed voting behaviour. The expected benefits of a change in government will be dependent on $n w(n) b$ where $n$ is the size of the population affected, $w(n)$ is the average weight given to them by the individual voters, and $b$ is the average perceived benefit. Assuming $w(n)$ is roughly constant once $n$ is large enough to swamp direct effects on the individual, and that the probability of a decisive vote is of the order of $1 / n$, the expected benefits of voting are roughly independent of the size of the electorate. Voter turnout will be determined mainly by $b$, the perceived difference between the parties, and by the closeness or otherwise of the election. (This approach, in which $b$ is a simple step-function, may be replaced by a more sophisticated one in which $b$ depends not only on the party elected, but on the size of its majority. This would be consistent with the fact that there is a substantial, though normally reduced, turnout in elections which are perceived as foregone conclusions.)

The model predicts voting behaviour in which personal selfishness does not play a significant role, but which is, nevertheless, not that of a pure utilitarian. The individual will place greater weight on interests which are 'closer to home' (this may be in a geographical or class sense), than on those of the populace at large.

Politicians will display a similar mix of selfishness and altruism. Selfishness will be most apparent in areas such as salaries and perquisites of office which are, in essence, a direct transfer from taxpayers to officeholders. On the other hand, in making legislative decisions, politicians will frequently put the 'public good', as they perceive it, ahead of their own welfare. This must be qualified in two ways. First, as with voters, interests 'close to home' are likely to weigh relatively heavily in the perceived public benefit. Second, even a purely altruistic politician must make some compromises on some issues in order to gain support on others. The role of lobbyists in this system is significantly reduced although, if anything, the possibility of forming lobbies is enhanced. In general, lobbyists must work by persuading voters or politicians, or both, of the desirability of the policies they are advocating. While the analysis of the behaviour of politicians raises many complex issues, I believe that the model described here is more consistent than the egoistic model with both the empirical work of writers such as Kalt and Kau and Rubin and with ordinary observation of the political process.

This relatively minor modification yields substantially improved predictions, compared to the orthodox public-choice theory model. Nevertheless, it is not sufficient to resolve all of the problems associated with the egoism model. 
First, Downsian arguments may still be applied, though with somewhat less force. For, if $w(n) b$ is greater than the cost of voting, $n w / n) b$ must be very large indeed, that is a change of government must greatly augment the voter's welfare. This is clearly 'unrealistic', a fact which should not worry followers of the positivist methodology, since it does not affect the main predictions of interest, but may well concern others. Second, in some areas, such as charitable giving, this model yields clearly incorrect predictions. This is pointed out by Margolis (1982), who proposes an alternative approach to the problem.

Margolis first uses evolutionary arguments, similar to those of the 'sociobiological' school, to argue that some degree of altruism is a more plausible psychological assumption than pure egoism. He points out the difficulties of a welfare function of the type described above, and argues instead that individuals divide their resources between self-interested activities, and those aimed at improving the welfare of society as a whole. The division will depend on the relative 'productiveness' of expenditure in the two areas. (This could, of course, be expressed in terms of a higher order welfare function, but Margolis argues against this, preferring to use dual utilities for selfish and grouporiented activities). Voting is then explained relatively easily. Assuming a significant difference between parties, and a non-zero chance of influencing the result (or the margin of victory, if this has policy effects), voting is a very costeffective way of promoting the interest of society.

One problem with Margolis' analysis is that he implicitly assumes that the group with which individuals (in their altruistic role) are concerned is that defined by a nation State. It is clearly possible for concerns to be broader than this (e.g. the human race) or narrower (farmers), or to cut across national categories altogether (the international working class). What must be stressed, however, is that political activity which is irrational from an egoistic viewpoint may be rational from a group-oriented viewpoint.

Approaches involving altruism have not received much formal development, and a great deal of work remains to be done. Nevertheless, I believe that they yield clearly superior explanations of political behaviour to the orthodox approach based on the assumption of egoism, while preserving the bulk of the analysis of market behaviour based on this assumption.

\section{Concluding Comments}

Many of the central predictions of orthodox public-choice theory do not stand up to empirical testing. Some of these failed predictions, such as the Downs' paradox, are well known, while others, such as those concerning the power of concentrated lobbies, have been repeatedly refuted by econometric tests. However, this has had virtually no effect on the expansion of research effort within the public-choice paradigm.

While this is an extreme case, it is one of a number of areas within economics where theory, if not directly contradicting the available evidence, has at least run far ahead of it. This situation does not seem to have altered much since the scathing analysis put forward by Leontief (1971). The problem is particularly severc in the teaching of economics where theory is often put forward with a confidence which completely belies its limited empirical validation.

McCloskey (1983) responds to this situation by arguing that persuasion or 'rhetoric' rather than empirical evidence is what matters; that is, in more pejorative terms, that economics is an ideology rather than a science. The example of public-choice theory would appear to support this view. While the 'rhetoric' of economics is that of a neutral science, the practice is frequently different.

Nevertheless, I believe that empirical testing is the appropriate way to discriminate between theories in economics, and that this must be accompanied by willingness to abandon theories which fail this testing. In the case of public-choice theory, this attitude would require fundamental changes. In particular, the postulate of individual egoism must be abandoned, or at least significantly modified. Some alternative approaches have been outlined above. Whatever approach is adopted, closer attention to the facts is vital.

\section{REFERENCES}

Anderson, K. (1980), The Political Market for Assistance to Australian Manufacturing Industries', Economic Record, 56, 132-44.

Arrow, K. (1951) Social Choice and Individual Values, Wiley, New York.

Ashenfelter, O. and Kelley, S. (1975), 'Determinants of Participation in Presidential Elections', Journal of Law and Economics, 18, 695-733.

Becker, G. (1976), The Economic Approach to Human Behoviour, University of Chicago Press, Chicago.

Black, D. (1958), The Theory of Committees and Elections, Cambridge University Press, Cambridge. 
Blaug, M. (1980), The Methodology of Economics: Or How Economists Explain, Cambridge University Press, Cambridge.

Boulding, K. (1969), 'Economics as a Moral Science', American Economic Review, 59, 1-12.

Brennan, G. and Buchanan, J. (1981), 'The Normative Purpose of Economic "Science": Rediscovery of an Eighteenth-century Method', International Review of Law and Economics, 1, 155-66.

(1982), The Power to Tax: Analytical Foundations of a Fiscal Constiturion, Cambridge University Press, Cambridge.

- (1983), 'Predictive Power and the Choice Among Regimes', Economic Journal, 93, 89-10s.

- (1984), 'Voter Choice: Evaluating Political Alternatives', American Behavioural Scientist, 28, 185-201.

Breton, A. (1974), An Economic Theory of Representative Government, Aldine Publishing Co. Ltd, Chicago.

Buchanan, J. (1975), The Limits of Liberty, University of Chicago Press, Chicago.

(1977). Freedom in Constitutional Contrast, Texas A \& M University Press, College Station.

Campbell, A., Converse, P., Miller, W. and Stokes, D. (1960), The American Voter, Wiley, New York.

Caves, R. (1976), 'Economic Models of Political Choice: Canada's Tariff Structure', Canadian Journal of Economics, 9, 278-300.

Dougan, W. (1984), 'Tariffs and the Economic Theory of Regulation', Research in Law and Economics, 6, 187-210.

Downs, A. (1957), An Economic Theory of Democracy, Harper \& Row, New York.

Fair, R. (1978), 'A theory of Extramarital Affairs', Jownal of Political Economy, 84, 45-62.

Finger, J., Hall, H. and Nelson, D. (1982), The Political Economy of Administered Protection', American Economic Review, 72, 452-66.

Friedman, M. (1953), Essays in Pasitive Economics, University of Chicago Press, Chicago.

Institute of Economic Affairs (1978), The Economics of Politics, IEA Readings No. 18.

Kalt, J. and Zupan, M. (1984), 'Capture and Ideology in the Economic Theory of Politics'. American Economic Review, 74, 249-70.

Kau, J. and Rubin, P. (1979), 'Self-interest, Ideology and Log-rolling in Congressional Voting', Journal of Law and Economics, 22, 365.

- (1981), Congressmen, Constituents and Contributors. An Analysis of the Determinants of Roll
Call Voting in the House of Representatives, KluwenNjjhoff.

Krueger, A. (1974), The Political Economy of the Rentseeking Society', American Economic Review, 64, 291-303.

Leontief, W. (1971), Theoretical Assumptions and Nonobserved Facts', American Economic Review, 61, 1-7.

Levine, M. and Plott, C. (1977), 'Agenda Influence and its Implications', Virginia Law Review, 631, 561-604.

Maloney, M. and McCormick, R. (1982), 'A Positive Theory of Environmental Quality Regulation', Journal of Low and Economics, 25, 99-124.

Margolis, H. (1982), Selfishness, Altruism and Rationality, Cambridge University Press, Cambridge.

McCloskey, D. (1983), 'The Rhetoric of Economics', Journal of Economic Literature, 21, 481-517.

McKelvey, R. (1976), 'Intransitivities in Multidimensional Voting Models and Some Implications for Agenda Control', Journal of Economic Theory, 12, 472-82.

McPherson, C. (1972), Tariff Structures and Political Exchange', unpublished Ph.D. thesis, University of Chicago, Chicago.

Mueller, D. (1979), Public Choice, Cambridge University Press, Cambridge.

Nie, N., Verba, S. and Petrocik, J. (1976), 'The Changing Americen Voter', Harvard University Press, Cambridge, Massachusetts.

Nordhaus, W. (1957), 'The Political Business Cycle', Review of Economic Studies, 42, 169-90.

Olson, M. (1965), The Logic of Collective Action, Harvard University Press, Cambridge.

Peltzman, S. (1984), 'Constituent Interest and Congressional Voting', Journal of Law and Economics, 27, $181-210$.

Pincus, J. (1975), 'Pressure Groups and the Pattern of Tariff', Joumal of Political Economy, $\boldsymbol{3}, 757-78$.

Quiggin, J. and Stoeckel, A. (1982), 'Protection, Income Distribution and the Rural Sector, Economic Papers, 1. 56-70.

Riker, W. and Ordeshook, P. (1968), 'A Theory of the Cakulus of Voting', American Political Science Review, 62, $25-42$.

Rowley, C. (1978), "Market "Failure” and Government "Failure"', pp. 29-44 in IEA (1978).

Tullock, G. (1972), 'Economic Imperialism', pp. 317-29 in J. Buchanan and R. Tollison (eds), Theory of Public Choice, University of Michigan Press, Ann Arbor. (1982), 'Why So Much Stability?', Public Choice, 37, 189-202. 